\title{
Magnetic anisotropy and debris-dependent rheological heterogeneity within stratified basal ice
}

\section{Paper}

Cite this article: Hopkins NR, Evenson EB, Bilardello D, Alley RB, Berti C, Kodama KP (2019). Magnetic anisotropy and debrisdependent rheological heterogeneity within stratified basal ice. Journal of Glaciology 65, 770-779. https://doi.org/10.1017/jog.2019.51

Received: 15 October 2018

Accepted: 10 July 2019

First published online: 5 September 2019

Key words:

Basal ice; ice rheology; glacial rheology; subglacial processes

Author for correspondence:

Nathan R. Hopkins,

E-mail: nhopkins1@tulane.edu (c) The Author(s) 2019. This is an Open Access article, distributed under the terms of the Creative Commons Attribution licence (http:// creativecommons.org/licenses/by/4.0/), which permits unrestricted re-use, distribution, and reproduction in any medium, provided the original work is properly cited.

\author{
Nathan R. Hopkins ${ }^{1}$, Edward B. Evenson², Dario Bilardello ${ }^{3}$, Richard B. Alley ${ }^{4}$ (D), \\ Claudio Berti ${ }^{5}$ and Kenneth P. Kodama ${ }^{2}$ \\ ${ }^{1}$ Earth and Environmental Sciences, Tulane University, LA, USA; ${ }^{2}$ Earth and Environmental Sciences, Lehigh \\ University, Bethlehem, PA, USA; ${ }^{3}$ Institute for Rock Magnetism, University of Minnesota, Minneapolis, MN, USA \\ ${ }^{4}$ Department of Geosciences, Pennsylvania State University, University Park, PA, USA and ${ }^{5}$ Idaho Geological \\ Survey, University of Idaho, Moscow, ID, USA
}

\begin{abstract}
Basal ice of glaciers and ice sheets frequently contains a well-developed stratification of distinct, semi-continuous, alternating layers of debris-poor and debris-rich ice. Here, the nature and distribution of shear within stratified basal ice are assessed through the anisotropy of magnetic susceptibility (AMS) of samples collected from Matanuska Glacier, Alaska. Generally, the AMS reveals consistent moderate-to-strong fabrics reflecting simple shear in the direction of ice flow; however, AMS is also dependent upon debris content and morphology. While sample anisotropy is statistically similar throughout the sampled section, debris-rich basal ice composed of semi-continuous mm-scale layers (the stratified facies) possesses well-defined triaxial to oblate fabrics reflecting shear in the direction of ice flow, whereas debris-poor ice containing mm-scale star-shaped silt aggregates (the suspended facies) possesses nearly isotropic fabrics. Thus, deformation within the stratified basal ice appears concentrated in debris-rich layers, likely the result of decreased crystal size and greater availability of unfrozen water associated with high debris content. These results suggest that variations in debris-content over small spatial scales influence ice rheology and deformation in the basal zone.
\end{abstract}

\section{Introduction}

A basal zone of ice that interacts with the glacier bed is common to many glaciers and ice streams. This zone is typically debris-rich and has a low concentration of air bubbles relative to the sedimentary englacial ice, indicating its subglacial origin (bubble-free ice may be formed in other ways as well; e.g. Luthi and others, 2009). The basal zone also commonly possesses internal structures, such as banding or zonation at various scales, which frequently display folding, boudinage or other deformational features. Basal ice such as that observed at Matanuska Glacier is derived from subglacial waters - both glacial melt and surface-derived which freezes and incorporates debris by processes of regelation or hydraulic supercooling (Alley and others, 1998). Within the basal zone, there is commonly a layer several meters thick that exhibits a banding - termed 'stratification' by Lawson $(1979 a)$ - that arises from alternating layers of debris-poor and debris-rich ice (Fig. 1). The mechanism by which this stratification arises is poorly understood, and might either reflect pseudo-seasonal hydraulic fluctuations at the glacier bed or be a foliation resulting from post-freeze-on segregation and deformation within the basal zone (Alley and others, 1998). The origin of this stratification is of interest because of its implications for ice flow and processes of subglacial sediment entrainment and transport. Additionally, in situ melting of stratified basal ice contributes to the formation of melt-out till, a not-uncommon type of till that until recently has been both variably and poorly understood (Larson and others, 2016).

Fabric - the preferred orientation of clasts, grains, particles and crystals - is a common tool used to learn about depositional and deformational processes. In glacial geology, 'macrofabric' refers to the orientation of macroscopic grains, commonly pebbles, and is an easy, low-cost way to investigate glacial processes. However, this tool is limited by grain size (i.e. application to fine-grained sediments requires special sample preparation and microscopic or other examination) and the potential for unintentional user bias (Chandler and Hubbard, 2008). Anisotropy of magnetic susceptibility (AMS) has a long history of application in structural geology as an indicator of relative strain in rocks (e.g. Borradaile, 1988; Pares, 2004; Ferre and others, 2014). AMS is dominantly controlled by the shape and distribution of magnetic grains (Tarling and Hrouda, 1993), and thus provides a robust, volume-averaged and objective alternative to traditional measurements of the fabric where environmental conditions and material properties are amenable to sampling and analysis.

In a novel investigation of the basal ice of Tunabreen, Svalbard, Fleming and others (2013) demonstrated the potential of the AMS method for evaluating deformation kinematics in the basal zone of modern glaciers. After collecting samples using a drill designed for the recovery of cores for paleomagnetic analysis, Fleming and others measured the AMS of a total of 61 samples from six sites located across the exposed terminus of the glacier. The samples 


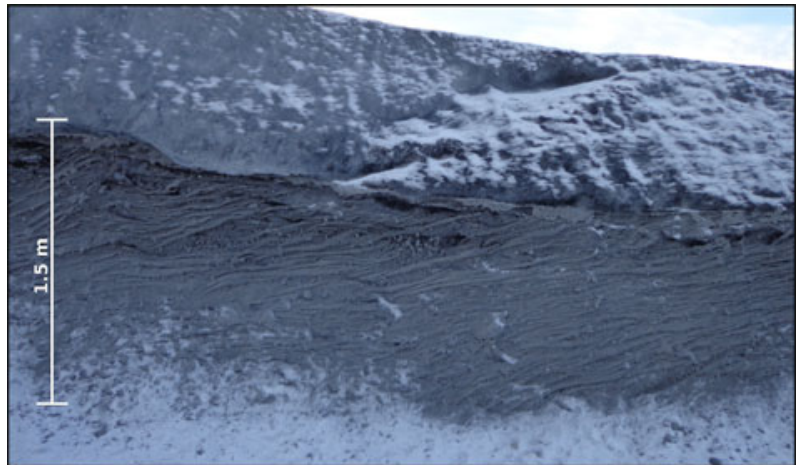

Fig. 1. Basal ice exposure near our sample location (see Fig. 2). Photograph looking toward the SW. Note the abrupt transition from the clean englacial ice, above, to the debris-rich stratified ice, and the consistent up-glacier (to the left) dip of the debrisrich horizons.

possessed a measurable AMS, dominated by the susceptibility of paramagnetic sediments. The diamagnetic susceptibility of ice contributed insignificantly to the AMS. The mean maximum AMS susceptibility axis paralleled ice flow direction, trending to the north $\left(359^{\circ}\right)$ with a $20^{\circ}$ plunge. The maximum susceptibility axes were also found to parallel macroscopic deformation structures, such as sheath folding, elongated bubbles and stretching lineations. Additionally, the similarity of the fabric of basal ice to that of subglacially deformed materials led the authors to postulate that the March (1932) model of grain rotation may also apply to the deformation kinematics of basal ice. Overall, the AMS results of Fleming and others provide further evidence that non-coaxial strain plays a significant role in the deformation of basal ice.

Because the basal zone is composed of distinct facies of ice with differing morphologies and concentrations of debris, we expect AMS to be variable within the basal zone and, perhaps, to reflect rheological variations. Herein, we apply the AMS technique to the stratified basal ice of Matanuska Glacier, Alaska, USA, to evaluate the nature and distribution of strain within the basal zone. Specifically, we use a dense sampling of two exposures to (1) characterize the magnetic mineralogy of the basal zone of Matanuska Glacier; (2) characterize the AMS ellipsoid and fabric of debris-rich and debris-poor ice facies; (3) evaluate the influence of debris concentration on the fabric in the basal zone. Subsequently, we discuss the implications our results have on our understanding of the rheology of debris-ice mixtures contextualized by a thorough understanding of the grain-scale forces acting to align the particles within the basal ice.

\section{Field setting}

The Matanuska Glacier (Figs 2a, b), located $\sim 150 \mathrm{~km} \mathrm{NE}$ of Anchorage, AK, USA, is an $\sim 48 \mathrm{~km}$ long temperate glacier, which drains NNW from the ice fields of the Chugach Mountains. The Matanuska is well-known for excellent exposures of stratified basal ice, and has a particularly well-developed stratification. The glacier has been remarkably stable throughout much of the Holocene (Williams and Ferrians, 1961). The terminal lobe of the Matanuska (Fig. $2 \mathrm{c}$ ) is $\sim 4 \mathrm{~km}$ wide, the eastern portion of which is stagnant and covered with supraglacial debris; the western, debris-free portion is active and is the location of this study.

During winter months, ice advance causes the terminus of the glacier to thrust over morainal debris and stagnant buried ice, exposing the base of the glacier and providing access to the basal zone. This phenomenon provides excellent exposures of the englacial ice and some or all of the basal ice, sometimes extending into subglacial sediments. The basal zone of the Matanuska was first described in detail by Lawson (1979a, $1979 b)$. The Matanuska is a remarkably well-studied glacier, so the discussion that follows is largely a summary of the relevant details from Lawson $(1979 a, 1979 b, 1981)$, as well as additional relevant observations published in the literature.

The basal zone of the Matanuska ranges from 1 to $15 \mathrm{~m}$ thick when exposed; however, the thicker exposures are packages of ice stacked by low-angle thrusts. Basal ice has been observed, at one time or another, along the entire width of the active portion of the glacier, and has been detected geophysically and traced up-glacier $\sim 300 \mathrm{~m}$ (Arcone and others, 1995; Lawson and others, 1998; Baker and others, 2003). Lawson $(1979 a, 1979 b)$ provided detailed descriptions of the englacial and basal zones, and identified facies useful for characterizing the ice. The englacial ice - the debris-free or nearly-debris-free glacier ice constituting most of the glacier can be subdivided into the diffuse and banded facies; however, the englacial zone is outside the scope of this work. The basal zone is characterized by three facies: dispersed, stratified and suspended. The dispersed facies is commonly found directly below the englacial ice, and the transition between the two is abrupt. This facies can be thin $(\sim 0.2 \mathrm{~m})$ to thick $(8 \mathrm{~m})$, and in some localities non-existent. Debris within the dispersed facies is uniformly distributed and rarely clustered; debris typically represents $8 \%$ of the sample by mass.

The stratified and suspended facies (Fig. 1) underly the dispersed facies, and the contact is well-defined, but irregular. The most striking feature of the basal ice is the apparent stratification that arises from alternating layers of debris-poor and debris-rich ice. The debris-poor suspended facies is composed of fine-grained ice (typically $<4 \mathrm{~mm}$, Lawson, $1979 \mathrm{c}$ ), and is generally bubble-free; when present, air bubbles are elongated in the direction of ice flow. Within these layers, debris is commonly present in irregularly shaped silt aggregates at grain intersections. The debris-rich stratified facies contains predominantly silt-to-coarse sand in welldefined semi-planar layers. In some cases, layers are ice-supported, and in others, ice is present only in the interstices between clasts. Clasts as large as cobbles are occasionally present, and are mostly subround and lack striations. Layers are generally semi-continuous at the scale of the exposure, and commonly dip up-glacier $10-15^{\circ}$. Debris layers are commonly $1-3 \mathrm{~cm}$ thick, and extend for several meters. See Larson and others (2016) for a complete description of the sedimentology of the stratified basal ice.

The freeze-on process for the basal zone of the Matanuska has been identified as hydraulic supercooling of subglacial waters rising from an overdeepening near the glacier terminus (Alley and others, 1998). An overdeepening beneath the active portion of the glacier is readily identified by a zone of heavy crevassing immediately up-glacier of the modern glacier terminus, and has been characterized geophysically (Lawson and others, 1998; Baker and others, 2003). In the summer months, frazil ice can be observed forming at vents near the glacier terminus (Lawson and others, 1998; Evenson and others, 1999). This frazil ice is produced as the pressure is released from supercooled water as it rises from the overdeepening, resulting in rapid ice crystal growth and entrainment of suspended and, in some cases, bedload sediments (Alley and others, 1998). Isotopic studies of the basal zone of the Matanuska indicate that rainfall runoff in addition to glacial melt is an important component of the basal waters, and that growth of the basal zone ice post-dates the production of bomb-produced tritium in the atmosphere (Lawson and Kulla, 1978; Strasser and others, 1998; Titus and others, 1999). 


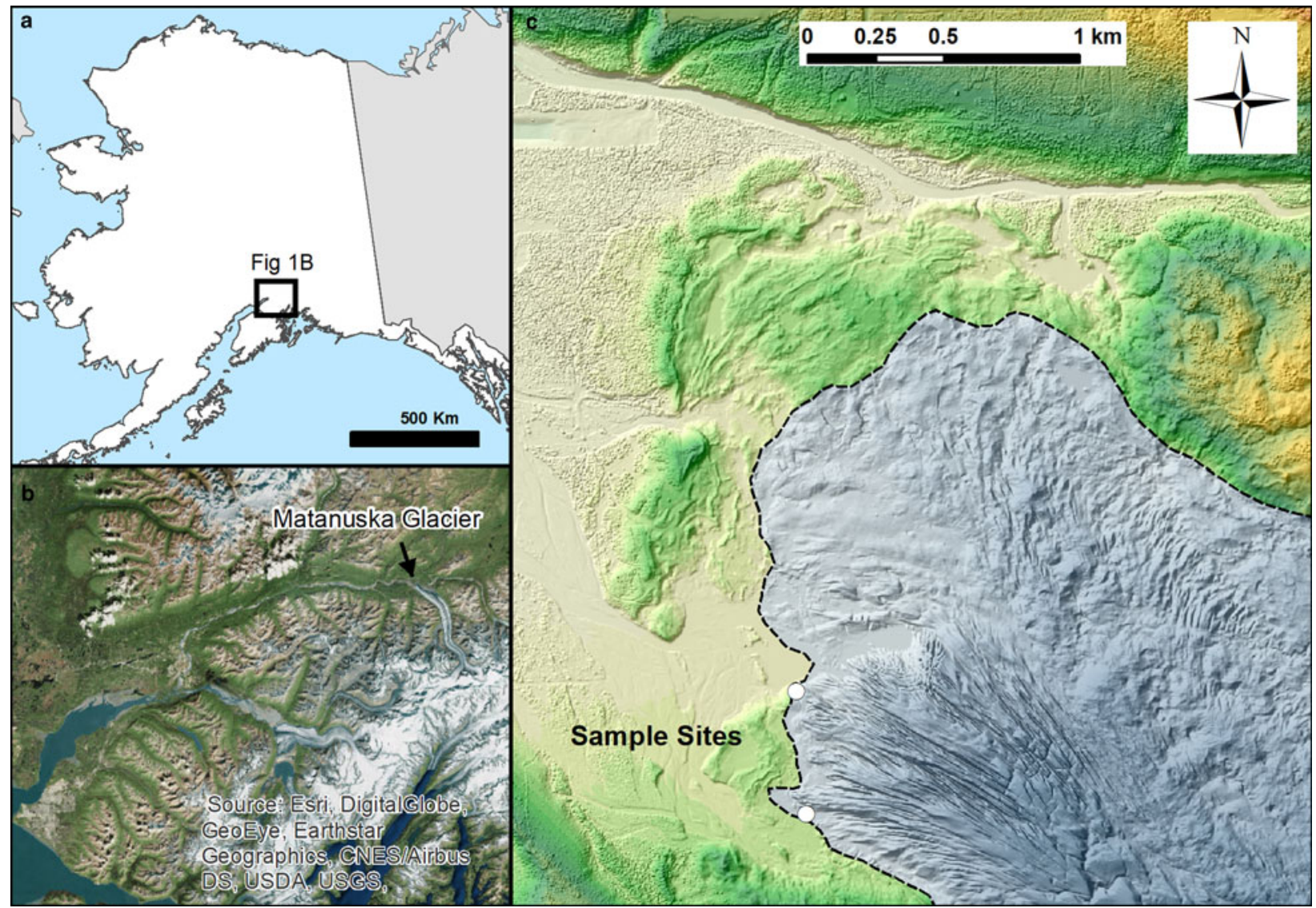

Fig. 2. (a) Location map indicating the study area in southern Alaska. (b) Satellite image of the Chugach Range, Anchorage Lowland and the Matanuska Valley, including the prominent Matanuska Glacier. (c) LiDAR DEM and hillshade of Matanuska Glacier's terminus, including the primary sampling sites and ice margin (dashed line and shading).

\section{Sampling and methodology}

The basal zone of Matanuska Glacier was sampled in two locations on the western front of the active portion of the glacier. The northern sample site (Fig. 2) provided an $\sim 1.5$ m-thick section of the stratified basal ice underlying a thin $(\sim 4 \mathrm{~cm})$ section of dispersed facies. Here, the layering within the stratified facies displays a relatively uniform up-glacier dip of $\sim 15^{\circ}$. At the section sampled, the basal zone was capped by $\sim 0.5 \mathrm{~m}$ of clean (debrisfree), englacial ice. Samples were collected for AMS analysis and determination of debris content from one vertical column extending from the upper contact of the basal zone to the base of the exposure (Fig. 3). Additional samples were collected at the southern sample site (Fig. 2), which exhibited easily collectable distinct stratified and suspended facies; these samples were analyzed separately and will be referred to as the 'facies samples'. At each site, large $(15 \mathrm{~cm} \times 15 \mathrm{~cm} \times 10 \mathrm{~cm})$ samples were cut using a concrete saw, oriented using a Brunton compass, and extracted from the exposure using a chisel and hammer. Orientation marks were carved into the samples, which were subsequently tightly sealed with plastic wrap and bagged to minimize sublimation during storage. Each sample collected was subsampled into $\sim 8 \mathrm{~cm}^{3}$ specimens and inserted into standard paleomagnetic sample boxes. In total, 267 specimens were retrieved from the column in Figure 3 for analysis at Lehigh University. The facies specimens (117 total) were visually classified as stratified or suspended facies, according to the dominance of suspended silt aggregates or stratified layers, and shipped to the Institute for Rock Magnetism, University of Minnesota for analysis. To minimize melting, samples were kept in a cooler with dry ice between cuts and measurements.
AMS was measured at Lehigh University using a KLY-3S Agico Kappabridge (Brno, Czech Republic) following the 15 static orientation scheme of Jelinek (1981). Additional specimens were measured at the Institute for Rock Magnetism, University of Minnesota, using an Agico MFK-1a susceptibility bridge with an automatic three-axis sample rotator. The orientationdependent susceptibilities were fit using the least-squares method to an AMS ellipsoid defined by the maximum $\left(k_{1}\right)$, intermediate $\left(k_{2}\right)$ and minimum $\left(k_{3}\right)$ susceptibility axes.

For this investigation, we will evaluate the AMS of basal ice in two ways. First we will evaluate the AMS ellipsoid of individual specimens using anisotropy $\left(P^{\prime}\right)$ and shape $(T)$ factors (Hrouda, 1982):

$$
\begin{gathered}
P^{\prime}=\exp \sqrt{2 \sum\left(\ln k_{i}-\ln k_{\text {mean }}\right)^{2},} \\
T=\left[\frac{2 \ln \frac{k_{2}}{k_{3}}}{\ln \frac{k_{1}}{k_{3}}}\right]-1 .
\end{gathered}
$$

Subsequently, we will investigate the fabric, a higher-order orientation analysis of the AMS ellipsoids contained within a sample. In our study, each sample contains a minimum of 30 specimens. Therefore, each fabric is a composition of 30 or more ellipsoids. This distinction is important, as the information content of the AMS ellipsoids and the fabric to which they contribute are different. 


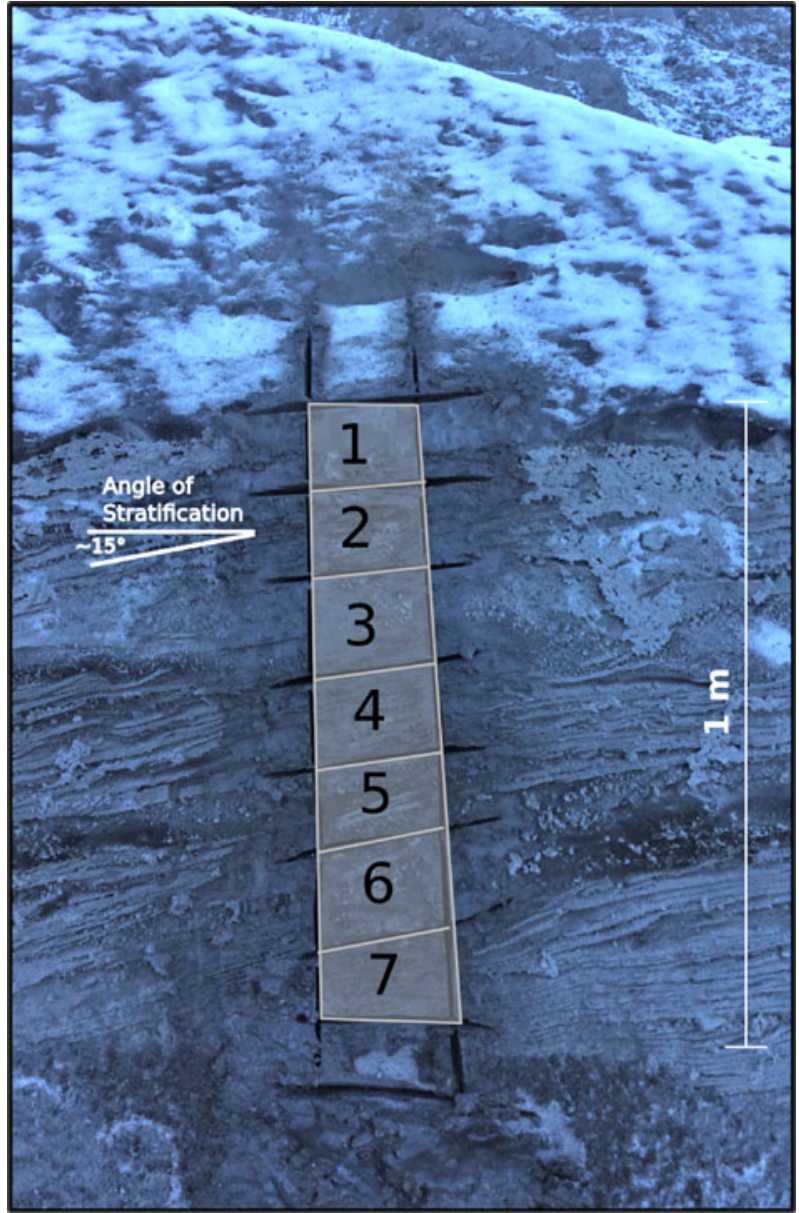

Fig. 3. Strategy for collecting seven specimens (numbered) from the uppermost $1 \mathrm{~m}$ of the $\sim 1.5 \mathrm{~m}$-thick section of basal ice. The snow-covered upper portion is debrisfree englacial ice. Specimens were not collected from the cuts above specimen 1 or below specimen 7 .

Following convention within glacial geology, the fabric orientations are characterized using the eigenvalue method of Mark (1973), wherein a symmetric second-rank tensor is fit to the distribution of each susceptibility axis (e.g. $\left.k_{1}\right)$ and described by the principal eigenvector orientations $\left(V_{1}, V_{2}\right.$ and $\left.V_{3}\right)$, and their associated eigenvalues $\left(S_{1}, S_{2}, S_{3}\right.$, with $\left.S_{1}+S_{2}+S_{3}=1\right)$. $V_{1}$ is the orientation of maximum clustering, the degree of which is described by $S_{1}$, where $S_{1}=0.33$ indicates an isotropic distribution and $S_{1}=1$ indicates a perfectly aligned population of axes. In the fabric analysis of till, it is common to analyze the fabric using the $k_{1}$ orientation, which becomes oriented parallel to the shear direction and possesses a characteristic up-glacier plunge relative to the shear plane defined by the $k_{2}$ axis (e.g. Hooyer and others, 2008; Iverson and others, 2008). Since the attitude of the shear plane is rarely known independently, magnetic fabrics must be evaluated using all three axes to avoid significant misinterpretations (Iverson, 2017). To further define fabric shapes and the clustering of axes, we employ the metrics of Benn (1994) and plot the isotropy $\left(I=S_{3} / S_{1}\right)$ and elongation $\left(E=1-S_{2} / S_{1}\right)$ for each susceptibility axis on a two-variable ternary diagram.

\section{Results}

\section{Magnetic mineralogy}

A series of magnetic experiments were conducted at the Institute for Rock Magnetism to determine the magnetic mineralogy of the basal ice. Leftover pieces of ice from cutting the cubic AMS samples were allowed to dry and the sediment was collected for measurement.

Low-temperature experiments were conducted on a Quantum Designs (San Diego, CA, USA) Magnetic Properties Measurement System. A specimen was cooled from 300 to $20 \mathrm{~K}$ in the presence of a $2.5 \mathrm{~T}$ field and the magnetic remanence (field cooling, remanence) was measured upon warming back to $300 \mathrm{~K}$. Subsequently, the specimen was cooled to $20 \mathrm{~K}$ in the absence of a field, a low-temperature saturation isothermal remanent magnetization (SIRM) of $2.5 \mathrm{~T}$ was applied, and the remanence was measured upon warming to $300 \mathrm{~K}$ (zero field cooling, remanence). The specimen was then subjected to a room temperature SIRM of $2.5 \mathrm{~T}$ and the magnetic remanence was measured upon cooling and warming between 300 and $20 \mathrm{~K}$. In all curves, the specimen goes through the $\sim 120 \mathrm{~K}$ magnetite Verwey transition (Verwey, 1939) and the $\sim 34 \mathrm{~K}$ pyrrhotite Besnus transition (Besnus, 1966), indicating that both magnetite and pyrrhotite are present (Fig. 4a).

High-temperature susceptibility measurements were performed on a KLY-2 Agico (Brno, Czech Republic) susceptibility bridge. Heating curves reveal a small peak followed by a decrease of susceptibility at $\sim 320^{\circ} \mathrm{C}$ consistent with the unblocking of pyrrhotite grains close to their Curie temperature (Dunlop and Özdemir, 1997) (Fig. 4b). A second broader increase of susceptibility is observed starting $\sim 500^{\circ} \mathrm{C}$ and is followed by a sharp drop at magnetite's Curie temperature $\left(580^{\circ} \mathrm{C}\right)$. The increase of susceptibility is attributed to the creation of new magnetite upon heating, likely from clay minerals, as confirmed by the enhanced susceptibility upon cooling. A small fraction of susceptibility persists to $\sim 650^{\circ} \mathrm{C}$ and is interpreted as the inversion of oxidized magnetite (maghemite) to hematite upon heating (Dunlop and Özdemir, 1997).

Unmixing of a backfield demagnetization curve (Maxbauer and others, 2016) reveals that two dominant populations of magnetic grains are present and can be fitted with two overlapping distributions centered at $\sim 15.7$ and $41.6 \mathrm{mT}$ (Fig. $4 \mathrm{c}$ ). The unmixing of backfield curves provides non-unique solutions, as evidenced by the uncertainty envelopes around the fitted components; however, the mean coercivities are consistent with a distribution of magnetite and pyrrhotite grains within the PSD grain size range.

These rock-magnetic data are mutually consistent, and demonstrate that the AMS of these glacial sediments is carried by a mixture of magnetite and pyrrhotite. Furthermore, the PSD grain size suggests the maximum and minimum principal susceptibility axes of these grains coincide with the long and short axes of the grains, indicating that these grains record normal susceptibility fabrics (e.g. Jackson, 1991). The data suggest that paramagnetic grains are also present, likely phyllosilicates and clay minerals, which may contribute to the AMS. However, their contribution is likely small in the presence of ferrimagnetic magnetite and pyrrhotite.

\section{Ice facies AMS characterization}

\section{Debris content}

Average debris content of the facies specimens is $38.4 \pm 18.8 \%$ by weight (wt.\%); individual specimens range from 1.2 to $67.1 \mathrm{wt} . \%$. The debris contents within the stratified and suspended facies are $52.0 \pm 9.74$ and $23.9 \pm 14.9$ wt.\%, respectively. These values are consistent with the previous observations at Matanuska Glacier (Lawson, 1979).

\section{AMS parameters}

AMS ellipsoids of the facies samples (Fig. 5a) vary considerably in both degree of anisotropy $\left(P^{\prime}\right)$ and shape $(T)$. This is 

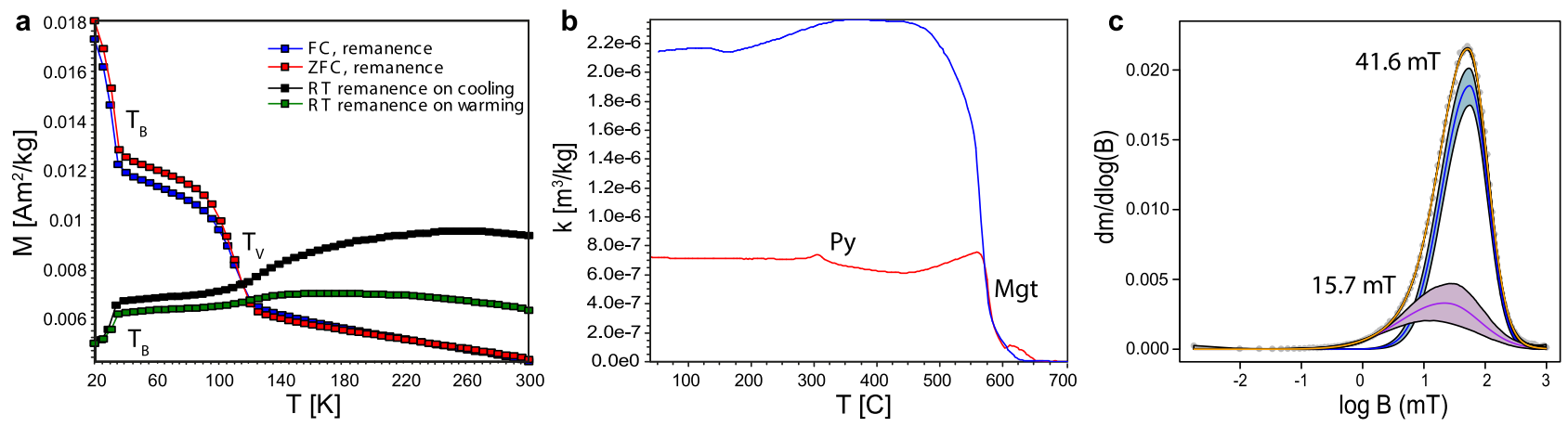

Fig. 4. (a) Low-temperature (de)magnetization data showing a pyrrhotite Besnus transition $\left(T_{\mathrm{B}}\right)$ at $\sim 34 \mathrm{~K}$ and a magnetite Verwey transition ( $\left.T_{\mathrm{V}}\right)$ at $\sim 120 \mathrm{~K}$ in the field-cooled (FC), zero field-cooled (ZFC) and room temperature saturation isothermal remanent (SIRM) magnetization curves. (b) High-temperature susceptibility. The heating (red) curve shows a peak in susceptibility preceding pyrrhotite's Curie temperature (Py) and a marked drop of susceptibility associated with magnetite's Curie temperature (Mgt). The cooling (blue) curve reveals an increase of susceptibility consistent with the production of magnetite upon heating. (c) Unmixing of backfield demagnetization data revealing two superimposed distributions of magnetic grains centered at coercivities of 15.7 and $41.6 \mathrm{mT}$, likely corresponding to magnetite and pyrrhotite (see text for details).
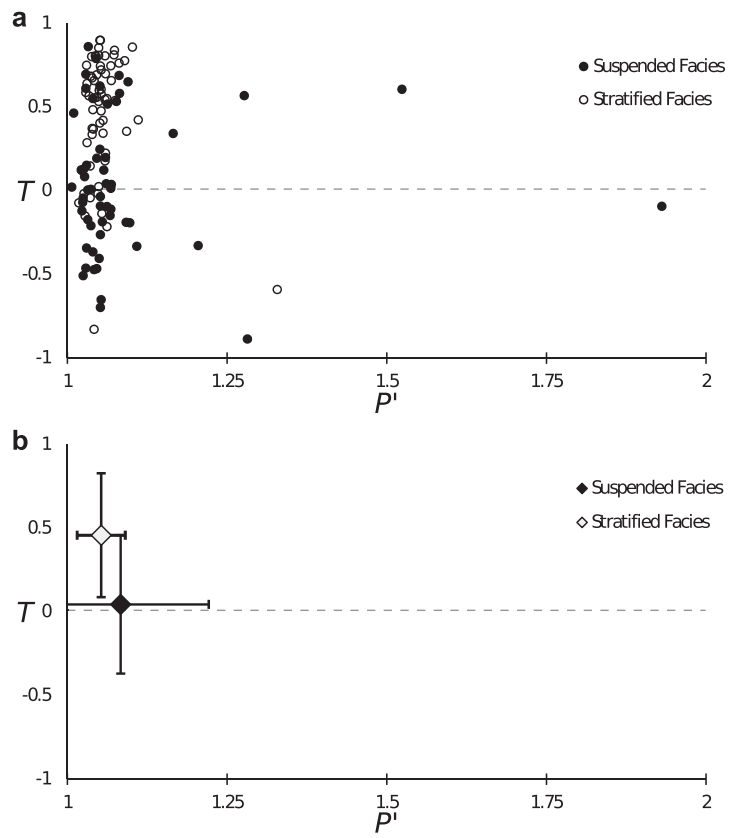

Fig. 5. Bivariate plot of specimen-level AMS anisotropy $\left(P^{\prime}\right)$ and shape $(T)$ factors for specimens classified as suspended and stratified facies (a) and facies mean anisotropies with 1-sigma error bars (b).

representative of the total population of samples, as has been observed in previous AMS investigations (e.g. Gentoso and others, 2012; Fleming and others, 2013; Hopkins and others, 2016). Taken as a whole, $T$ values indicate dominantly triaxial to oblate (positive) fabrics, but range from nearly perfectly prolate $(-0.89)$ to nearly perfectly oblate (0.9). Variation of $T$ is also large (mean std dev. of 0.4 ). $P$ ' shows significantly less variability. When samples are classified according to facies (Fig. 5b), anisotropy of the stratified facies is less variable $\left(P^{\prime}=1.05 \pm 0.04\right)$ and the shape is consistently oblate $(T=0.46 \pm 0.37)$. The AMS of the suspended facies is dominantly triaxial with $P^{\prime}$ values similar to, and sometimes much higher than, the stratified facies.

\section{AMS fabric}

The characteristic AMS fabric of each facies is markedly different (Fig. 6). The stratified facies possesses a well-developed, girdled fabric with a $V_{1}$ parallel to ice flow and plunging up-glacier $17.5^{\circ}$ within the plane of the stratification. Intermediate axes concentrate near horizontal, and the minimum axes are tightly

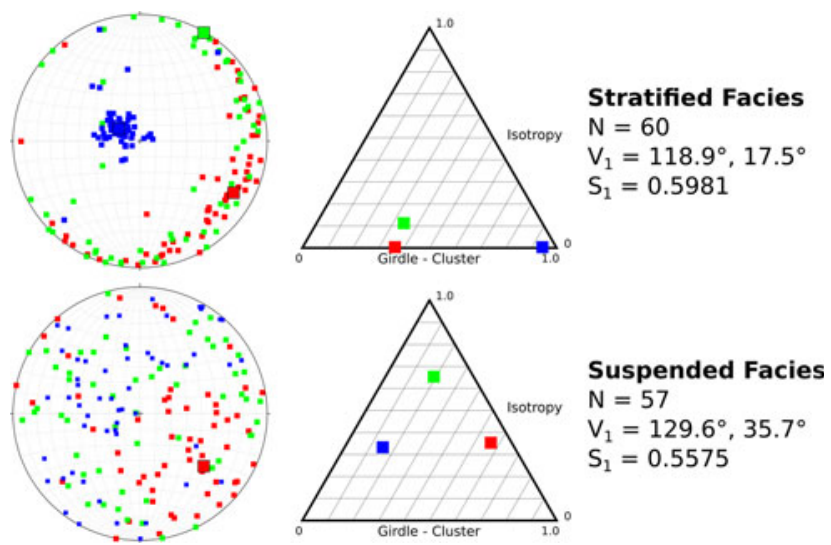

Fig. 6. Stereographic projections in a geographic coordinate system (left) and ternary shape diagrams (center) of AMS fabrics for basal ice facies. Individual AMS $k_{1}$ (red), $k_{2}$ (green) and $k_{3}$ (blue) axes are displayed using small squares; $V_{1}$ axes are presented using large squares for axes with $E>0.5$.

clustered perpendicular to the $k_{1}-k_{2}$ plane. In contrast, the suspended facies possesses a nearly isotropic fabric.

\section{Fabric: vertical distribution}

AMS fabrics for each sample from Figure 3 are presented in Figure 7. Sample 1, the uppermost fabric spanning the englacial, dispersed and stratified facies of ice, possesses a near random fabric for all the susceptibility axes. This specimen is also characterized by low debris content (17 $\pm 18 \mathrm{wt} . \%)$. All lower samples are exclusively within the stratified facies of ice, and possess anisotropic fabrics (Fig. 7). Specimens 2, 4, 5 and 7 display significant clustering of their $k_{1}$ axes $\left(S_{1}>0.6, E>0.5\right)$, and the $V_{1}$ trends for these fabrics are parallel or sub-parallel to the known ice flow direction (NW). These samples generally display insignificant plunge $\left(\leqslant 5^{\circ}\right)$ down-glacier, except for the lower-most fabric (sample 7$)$. Sample 7 possesses the strongest fabric of this section $\left(S_{1}=\right.$ $0.8565)$, and plunges $16^{\circ}$ up-glacier.

Fabric shape parameters, characterized using the ternary plots of Benn (1994), are shown in column 5 of Figure 7 and Table 1. Three of the four fabrics discussed above possess significant clustering around all three axes, with specimens 4 and 6 being the exception. The two specimens discussed above $(3,6)$ whose $k_{1}$ axes do not parallel ice flow display girdle fabrics within the $k_{1}-k_{2}$ plane. All fabrics within the stratified facies possess significant clustering around the $k_{3}$ axis, and in all cases this axis is near-vertical. 


\begin{tabular}{|c|c|c|c|c|c|}
\hline AMS Fabric & $k_{1}$ orientations & $k_{1}$ rose & Fabric Statistics & Fabric Shape & Sample Description \\
\hline & & & $\begin{array}{l}\text { Sample 1 } \\
N=37 \\
V_{1}=208.6^{\circ}, 35.1^{\circ} \\
S_{1}=0.4149\end{array}$ & & $\begin{array}{l}\text { Composite of Englacial, } \\
\text { Dispersed, and Stratified } \\
\text { Facies } \\
\text { Max. Grain Size: Pebble (M) } \\
\text { Debris (Wt. \%): } 16.6 \pm 18.2\end{array}$ \\
\hline & & & $\begin{array}{l}\text { Sample } 2 \\
N=55 \\
V_{1}=327.5^{\circ}, 5.1^{\circ} \\
S_{1}=0.6885\end{array}$ & & $\begin{array}{l}\text { Stratified Facies } \\
\text { Max. Grain Size: Pebble (M) } \\
\text { Debris (Wt. \%): } 46.7 \pm 7.4\end{array}$ \\
\hline & & & $\begin{array}{l}\text { Sample } 3 \\
N=34 \\
V_{1}=057^{\circ}, 03^{\circ} \\
S_{1}=0.5885\end{array}$ & & $\begin{array}{l}\text { Suspended Facies } \\
\text { Max. Grain Size: Sand (VF) } \\
\text { Debris (Wt. \%): } 25 \pm 3.7\end{array}$ \\
\hline & & & $\begin{array}{l}\text { Sample } 4 \\
N=37 \\
V_{1}=329.9^{\circ}, 3.2^{\circ} \\
S_{1}=0.6668\end{array}$ & & $\begin{array}{l}\text { Stratified Facies } \\
\text { Max. Grain Size: Pebble (C) } \\
\text { Debris (Wt. \%): } 58.5 \pm 8.0\end{array}$ \\
\hline & & & $\begin{array}{l}\text { Sample 5 } \\
N=39 \\
V_{1}=311^{\circ}, 0.1^{\circ} \\
S_{1}=0.6819\end{array}$ & & $\begin{array}{l}\text { Stratified Facies } \\
\text { Max. Grain Size: Pebble (C) } \\
\text { Debris (Wt. \%): } 47.7 \pm 14.2\end{array}$ \\
\hline & & & $\begin{array}{l}\text { Sample } 6 \\
N=30 \\
V_{1}=3.9^{\circ}, 34.6^{\circ} \\
S_{1}=0.5330\end{array}$ & & $\begin{array}{l}\text { Stratified Facies } \\
\text { Max. Grain Size: Pebble (VF) } \\
\text { Debris (Wt. \%): } 45.7 \pm 11.3\end{array}$ \\
\hline - & & & $\begin{array}{l}\text { Sample } 7 \\
N=35 \\
V_{1}=143^{\circ}, 16.1^{\circ} \\
S_{1}=0.8565\end{array}$ & & $\begin{array}{l}\text { Stratified Facies } \\
\text { Max Grain Size: Pebble (VF) } \\
\text { Debris (Wt. \%): } 45.9 \pm 5.9\end{array}$ \\
\hline
\end{tabular}

Fig. 7. AMS fabrics for each sample. Fabrics are presented in lower-hemisphere stereographic projections in a geographic coordinate system, with north toward the top of the page. Ice flow is to the NW. Individual AMS $k_{1}$ (red), $k_{2}$ (green) and $k_{3}$ (blue) axes are displayed using small squares; $V_{1}$ axes are presented using large squares for axes with $E>0.5$. Column 2 (from left) presents $k_{1}$ orientations with 2 -sigma Kamb contours. Column 3 presents $k_{1}$ rose diagrams. $k_{1}$ fabric statistics and $V_{1}$ trend and plunge are shown in column 4 . Two-variable $(E, I)$ ternary shape diagrams are presented in column 5 . Specimen sample descriptions and dominant facies are shown in column 6

The bulk $k_{1}$ fabric of all specimens (Fig. 8) in this section parallels ice flow $\left(V_{1}=316^{\circ}, 2^{\circ}\right)$, but displays weak clustering $\left(S_{1}=\right.$ 0.5506). Fabric shape $(I=0.213 ; E=0.403)$ indicates that the $k_{1}$ axes are weakly girdled in the horizontal plane, which is to be expected from averaging the clustered, girdled and isotropic fabrics displayed above. The girdle is better described as a bimodal distribution, with one cluster parallel to ice flow $\left(315^{\circ}\right)$ and another oriented perpendicular to flow, possibly representing an intersection lineation or switching of the $k_{1}$ and $k_{2}$ principle axes. The perpendicular $k_{1}$ orientations are largely sourced from samples 3 and 6, and possess anisotropy ellipsoids otherwise typical of the larger measured population.

\section{Relationships between fabric parameters and debris content}

Figure 9 explores the relationship between key descriptive measures of fabric and debris content. Consistent with the similar $S_{1}$ values for each facies, the strength of the fabric defined by the $k_{1}$ axes increases only slightly with increasing debris (Fig. 9a). Strength of the $k_{3}$ axis fabric shows a greater increase. Fabric elongation increases with increasing debris, while fabric isotropy decreases (Figs 9b, c). This relationship is significantly more pronounced for the $k_{3}$ axes, as would be expected for fabrics with $k_{1}$ and $k_{2}$ axes girdled within the shear plane.

\section{Discussion}

Fleming and others (2013) found that AMS aligns with the deformation inferred from the structures observed in basal ice of a surge-type glacier, supporting the use of magnetic properties as a proxy for deformational history (see 'Introduction' section). We provide a brief review here of some of the physical processes controlling the orientation of magnetic particles (inclusions) in ice, finding broad support for Fleming and others (2013), but with some nuance. Subsequently, we offer two potential explanations of the observed AMS of the basal ice of Matanuska Glacier.

Within a crystal at stresses and temperatures typical of glaciers, ice deforms almost entirely by dislocation glide on basal planes, but with no crystallographically preferred glide direction in those basal planes (see, e.g. Jacka and Budd, 1989; Cuffey and Paterson, 2010; Alley, 1992 for reviews). Because polycrystalline glacier ice rarely if ever is deposited with its basal planes oriented 
Table 1. Sample debris content (weight \%), fabric strengths $\left(S_{1}\right)$ and fabric shape characteristics (I \& E)

\begin{tabular}{|c|c|c|c|c|c|c|c|c|c|c|}
\hline \multirow[b]{2}{*}{ Specimen name } & \multirow[b]{2}{*}{ Debris content } & \multicolumn{3}{|c|}{$S_{1}$} & \multicolumn{3}{|c|}{ Isotropy (I) } & \multicolumn{3}{|c|}{ Elongation $(E)$} \\
\hline & & $k_{1}$ & $k_{2}$ & $k_{3}$ & $k_{1}$ & $k_{2}$ & $k_{3}$ & $k_{1}$ & $k_{2}$ & $k_{3}$ \\
\hline 1 & $16.6 \pm 18$ & 0.4149 & 0.3979 & 0.4460 & 0.5095 & 0.6127 & 0.5993 & 0.0991 & 0.0995 & 0.3572 \\
\hline 2 & $46.7 \pm 7.4$ & 0.6885 & 0.6837 & 0.8115 & 0.1182 & 0.1542 & 0.7592 & 0.6459 & 0.6914 & 0.8645 \\
\hline 3 & $25 \pm 3.7$ & 0.5885 & 0.4502 & 0.6842 & 0.0855 & 0.5789 & 0.1798 & 0.3862 & 0.3576 & 0.7181 \\
\hline 4 & $58.5 \pm 8$ & 0.6668 & 0.6376 & 0.9467 & 0.0141 & 0.0660 & 0.0109 & 0.5142 & 0.4976 & 0.9546 \\
\hline 5 & $47.7 \pm 14$ & 0.6819 & 0.6193 & 0.8559 & 0.0565 & 0.1807 & 0.0519 & 0.5900 & 0.5660 & 0.8835 \\
\hline 6 & $45.7 \pm 11$ & 0.5330 & 0.4981 & 0.7577 & 0.1811 & 0.2586 & 0.1435 & 0.3049 & 0.2508 & 0.8501 \\
\hline 7 & $45.9 \pm 5.9$ & 0.8565 & 0.8335 & 0.9340 & 0.0237 & 0.0496 & 0.0153 & 0.8563 & 0.8498 & 0.9446 \\
\hline Stratified facies & $52 \pm 9.7$ & 0.5981 & 0.5656 & 0.9093 & 0.0382 & 0.1176 & 0.0364 & 0.3663 & 0.3497 & 0.9367 \\
\hline Suspended facies & $23.9 \pm 15$ & 0.5575 & 0.4088 & 0.4581 & 0.3609 & 0.6443 & 0.3327 & 0.5672 & 0.1981 & 0.1497 \\
\hline
\end{tabular}

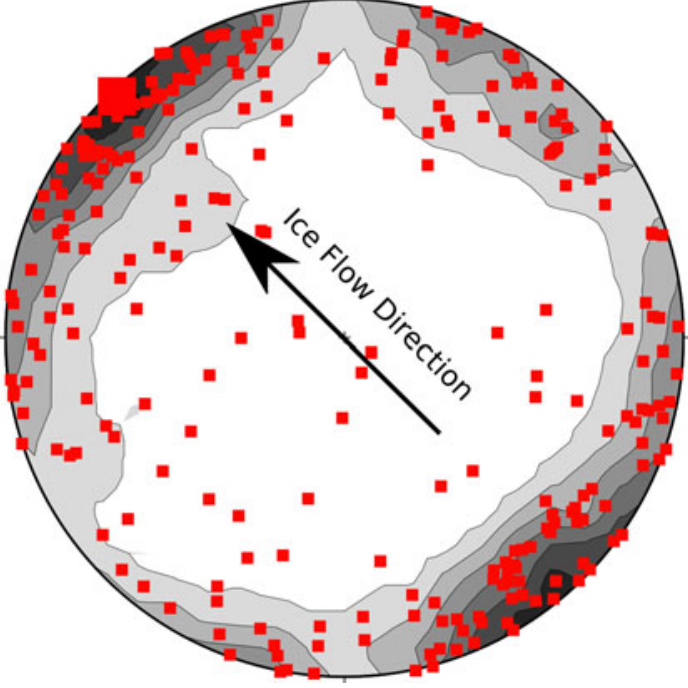

Fig. 8. Stereographic projection of all specimen AMS $k_{1}$ orientations (small squares) from the northern sample site contoured using 2-sigma Kamb contours, mean $V_{1}$ (large red square) and ice flow direction are also shown.

for easy glide in the stress state of the glacier, this restriction of glide to basal planes causes incompatible deformation between neighboring grains, which is accommodated by grain rotation, grain-boundary sliding, and diffusion and deformation focused in the regions of potential overlap or gaps between neighboring grains. Additional grain-boundary sliding may also occur, contributing to the bulk deformation (Goldsby and Kohlstedt, 2001).

The grain rotation associated with incompatible deformation of adjacent grains leads to the evolution of lattice-preferred orientations, with $c$-axes (the normal to the basal planes) rotating toward compressive axes in the large-scale stress field under 'pure' shear and rotating toward the normal to the shear plane under simple shear. This has the effect of making the ice harder for additional pure shear deformation, by reducing the resolved shear stress on basal planes, but making the ice softer in simple shear by aligning the shear planes of individual crystals with the shear plane of the glacier. Grain deformation also causes elongation of grains, and thus elongation and preferred orientation of grain boundaries.

This evolution of the grain-boundary structure and of $c$-axis fabric is opposed by additional processes, including subdivision of grains by strengthening of subgrain boundaries formed by interactions among dislocations, and by nucleation and growth of new, strain-free grains, which generally occurs with $c$-axes at high angles to stress axes such that there is a large resolved shear stress on the basal planes of the new grains. Under some conditions, a steady state may be reached in which nucleation and growth of new grains balance the deformation of old grains, producing a constant average grain size, grain shape, $c$-axis fabric, etc. Under other conditions, these characteristics continue to evolve with deformation.

Broadly, the net effect of simple-shear deformation of polycrystalline ice is to rotate grains such that their basal planes parallel the shearing direction, generally with some tendency to develop preferred orientation of grain boundaries also parallel to the shearing direction, and with adjacent grains experiencing similar deformation. Under pure shear, ice evolves toward basal planes in a 'hard' orientation, and during this evolution, adjacent grains deform in somewhat different ways. Under high stresses, nucleation and growth of new, strain-free grains occur with basal planes oriented at high angles to the applied stresses. In pure shear, this softens the ice but maintains incompatible deformation in adjacent grains. Some uncertainty remains about the onset, if any, of such nucleation-and-growth recrystallization in simple shear (Jacka and Budd, 1989). Such recrystallization is suppressed by high impurity or particulate concentrations that tend to slow or stop the migration of grain boundaries. Glaciers thus often contain relatively impure ice with a strong $c$-axis clustering that is deforming rapidly in simple shear, adjacent to 'cleaner' ice with a $c$-axis girdle or other relatively dispersed fabric.

Studies of the $c$-axis fabric and grain size of Matanuska Glacier are severely hampered by the difficulty of cutting thin sections through the ice with such high debris concentrations without causing localized melting (e.g. Ensminger and others, 2001). Observations of sublimated surfaces in winter confirm expectations that the higher debris concentrations of the stratified facies are associated with finer-grained ice than in the suspended facies. Modern techniques such as electron backscatter diffraction might be applied in future targeted studies, but at present we lack $c$-axis data on the ice studied. Analogy to other settings suggests that the fine-grained high-debris-concentration stratified-facies ice has $c$-axes clustered toward the normal to the layering, and that the coarser-grained lower-debris-concentration suspended-facies ice has either a similar fabric or a multi-maximum girdle centered on the normal to the layering (e.g. Samyn and others, 2008).

Non-spherical inclusions in the ice are rotated by flow, and spherical but deformable inclusions (e.g. bubbles) are deformed and then rotated. Inclusion orientations then can be used to interpret strain at the grain scale (Fegyveresi and others, 2018), as reviewed briefly here. 

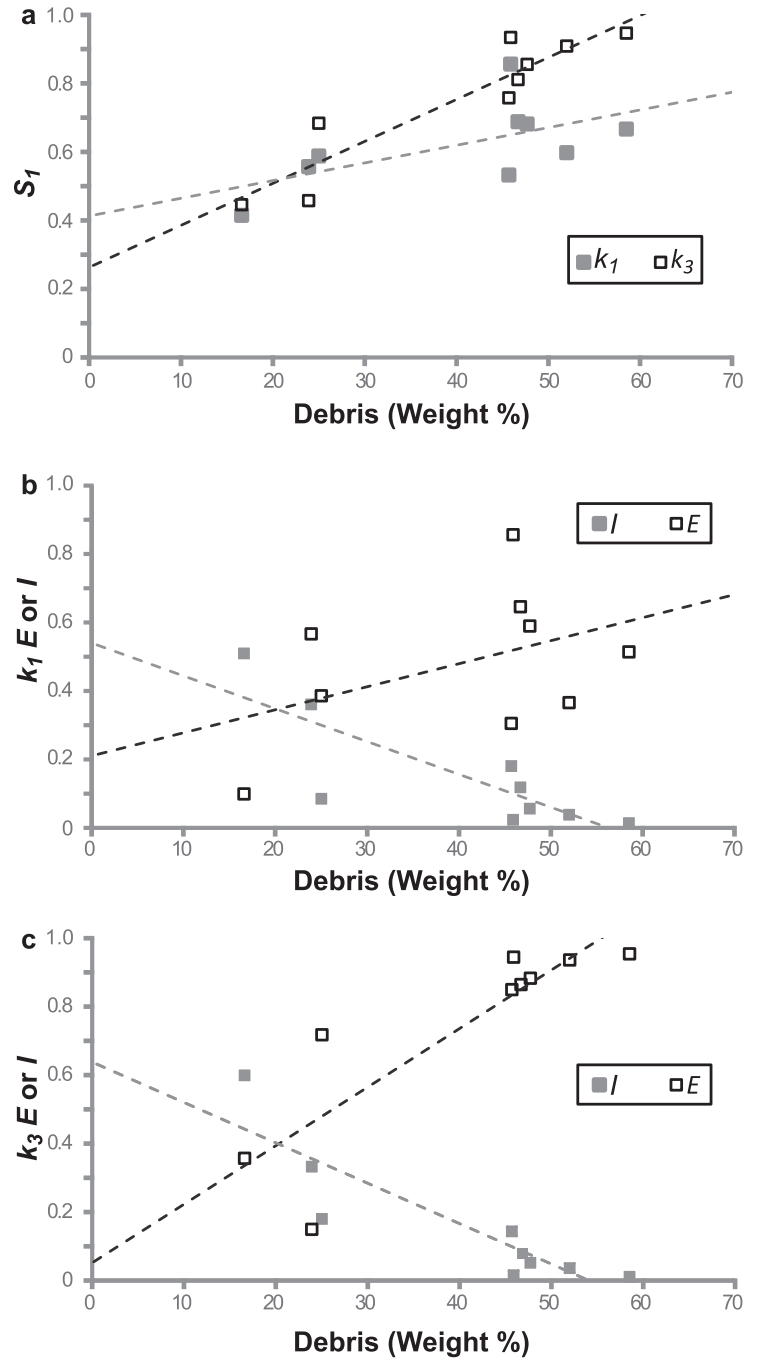

Fig. 9. Bivariate plots of fabric strength as measured by $S_{1}(a)$, fabric shape characteristics $(E, I)$ for $k_{1}$ fabrics (b) and fabric shape characteristics $(E, I)$ for $k_{3}$ fabrics (c).

The magnetic inclusions in Matanuska Glacier basal ice likely include combinations of more-or-less prolate magnetic ellipsoids of ferrimagnetic magnetite and pyrrhotite and more-or-less oblate ellipsoids of paramagnetic phyllosilicates. In temperate ice such as the Matanuska Glacier, these mineral inclusions are likely separated from the ice by meltwater, producing a free-slip boundary. Sufficient cooling would increase coupling between ice and inclusions, but persistent pseudo-liquid layers would likely allow continuing slip for temperatures within a few degrees of the bulk melting point, with great cooling required to fully couple ice and inclusions (Dash and others, 2006). For a free-slip boundary, pure shear in ice will tend to orient prolate inclusions in the elongation direction, and oblate inclusions with their short axis in the direction of greatest compression; simple shear will orient prolate inclusions in the shear direction and oblate inclusions in the shear plane (e.g. March, 1932; Ghosh and Ramberg, 1976; Ildefonse and Mancktelow, 1993). A no-slip boundary may allow an inclusion to rotate through the shear plane in simple shear, but with the slowest rotation near the shear plane, weakening the strength of fabric developed but not eliminating it, and maintaining the same relation to the stress state.

For any inclusion contained fully within a single ice crystal, this indicates that the direction of maximum elongation will rotate to align with the shear direction in the basal plane, with the minimum elongation normal to the shear plane. For a large inclusion crossing a grain (crystal) boundary, the situation may be somewhat complex, with influence from shear within both grains and from shearing in the grain boundary; however, the strong discontinuity in the grain boundary seems likely to dominate, so the inclusion would tend to be oriented with maximum elongation in the shear direction and minimum elongation normal to the grain boundary.

Triaxial (i.e. $k_{1}>k_{2}>k_{3}$ ) to girdle magnetic fabrics oriented sub-parallel to ice flow direction consistent with simple shear along a sub-horizontal shear plane dominate the basal ice of the Matanuska Glacier. This observation is also consistent with macrofabrics described in the basal zone of the Matanuska Glacier (Lawson, 1979; Hart, 1995), and is in general agreement with the AMS fabrics of Fleming and others (2013). Macrofabrics of the Matanuska are commonly moderately strong and plunge up-glacier, commonly within the plane of the stratification (Lawson, 1979), as would be expected under simple shear and as is commonly observed in subglacial tills. Up-glacier plunge is also observed in the magnetic fabrics of Fleming and others (2013). The same relationship is observed here. Simple shear within the basal zone has been suggested previously for other glaciers based upon macroscopic structures, including folds, boudinage, pressure shadows and rotational clasts (Hubbard and Sharp, 1989; Hart, 1998). These features are rarely observed at the Matanuska Glacier.

Magnetic anisotropy at the specimen-level is similar in debrisrich and debris-poor Matanuska Glacier ice (Fig. 5); however, averaging over multiple specimens produces isotropic to weakly developed magnetic fabrics in debris-poor ice, while debris-rich ice fabrics are well-developed with the $k_{1}-k_{2}$ axes girdled within the plane of stratification. Based on these magnetic fabrics, AMS indicates higher strain within debris-rich stratified facies ice but much less strain within debris-poor ice, or else the effects of recrystallization of ice crystals opposing the effects of strain on the magnetic fabric. The magnitude of strain indicated within debris-rich layers is perhaps variable; however, in most cases, it is significant. Fabric strengths reported here are comparable to AMS fabric strengths of deforming till beds (Shumway and Iverson, 2009; Gentoso and others, 2012; Vreeland and others, 2015; Hopkins and others, 2016); however, given the expected significant differences in the deformation style of basal ice and till, direct comparisons should be avoided. We suggest, as did Fleming and others (2013), that further work focusing on experimentally sheared debris-ice mixtures is needed.

There is no apparent trend in fabric strength throughout the $\sim 1.5 \mathrm{~m}$ column sampled in this study. This is perhaps surprising (cf. Hart, 1995), because the progressive growth of basal ice on the bottom of the glacier means that the uppermost samples are older than deeper ice. Several explanations are possible, and more than one mechanism may have contributed. Because the basal ice is thicker than the sampled interval (see 'Field setting' section), we have not characterized the full range of behavior, and there may be a trend that we lack the sensitivity to detect. Time evolution of basal strain rate during accretion as the ice flowed out of the overdeepening, coupled with depth variation of strain rate within the accreted ice from depth variation in stresses, could enhance or cancel depth variation in cumulative strain. We note again that while samples presented in Figure 7 were classified according to dominant facies, individual specimens were not; thus, the strength of fabrics in Figure 7 may not be directly comparable or a reliable indicator of relative strain, because each fabric is likely a composite of both stratified and suspended ice facies.

The rheology of basal ice is significant for glacial dynamics, including subglacial sediment transport and vertical deformation profiles (e.g. Cuffey and others, 2000). However, several mechanisms are involved, acting at rates affected by several factors (Hubbard and Sharp, 1989; Benn and Evans, 2014; Moore, 
2014), such that adding debris to ice may either harden or soften it for further deformation (Ting and others, 1983; Moore, 2014). Significant factors include debris content, ice crystal size, ice fabric and the presence of unfrozen water.

While field evidence indicates that increasing debris content typically weakens ice and allows for increased and more rapid deformation (Brugman, 1983; Fisher and Koerner, 1986; Echelmeyer and Zhongxiang, 1987; Cohen, 2000), laboratory studies often indicate an apparent 'hardening' of ice associated with increasing debris concentrations (e.g. Hooke and others, 1972; Baker and Bergerich, 1979; Nickling and Bennet, 1984). This discrepancy reflects the competing relationships between the variables mentioned above. Crystal size impacts ice strength, such that fine-grained ice tends to deform more readily, with grain size inversely related to debris content (Baker, 1978; Baker and Bergerich, 1979; Cuffey and others, 2000). Therefore, increasing debris content may cause progressively smaller ice crystals, which in turn shifts more of the debris into grain boundaries or their intersection such that ice in debris-rich layers can be largely interstitial. Microstructures identified within the debris-rich basal zone of the Taylor Glacier suggest the importance of unfrozen water, which may allow slip across interfacial water films (Samyn and others, 2005, 2009). Thus, we consider it highly likely that deformation is concentrated in the debris-rich layers of the stratified basal ice as a result of decreased ice grain size and greater availability of unfrozen water associated with high debris and, presumably, solute content, and that the facies-dependent fabrics (Fig. 8) support that conclusion.

It is also possible that a scale-dependent bias contributes to our results. In the suspended facies, debris is concentrated into $\mathrm{mm}$-scale clots at the intersections of coarse-grained ice. Within a representative $8 \mathrm{~cm}^{3}$ specimen, only a few clots are present. Sample anisotropy ( $P$, , Fig. 5$)$ is comparable to that of the stratified facies or even slightly stronger, indicating alignment within the clots, which may reflect some combination of cumulative strain and surface-tension effects. However, the orientation of the anisotropy may not align with the bulk shear direction because of local grain-scale deviations in stress and strain rate, which are expected under many circumstances, as described above. Averaging over many specimens then would yield the weak fabric observed in the suspended facies. In the finer-grained stratified facies with its greater debris concentration, local deviations of deformation from the bulk strain field are more fully sampled within a small volume, yielding weak specimen anisotropy but strong fabric. Based on our data and the results from other sites, we consider it likely that both mechanisms contribute: deformation is localized in the finer-grained layers with higher debris concentration, and the sampling scale of the AMS influences the results.

\section{Conclusions}

AMS fabric analysis within stratified basal ice of Matanuska Glacier supports the occurrence of simple shear within the basal zone, as expected physically and as observed for many other glaciers and ice streams. At the centimeter scale of individual AMS specimens, significant anisotropy occurs in both finer-grained ice with higher debris concentration and coarser-grained ice with sparser debris localized in clots. The finer-grained ice shows a stronger AMS fabric indicating more-consistent orientation of deformation in adjacent samples, likely both because of higher strain in the finer-grained ice, and because averaging over more grains in a single sample of finer-grained ice more completely removes the effects of local grain-scale deviations of deformation from the large-scale average. Simple shear parallel to ice flow appears to dominate. Future work is needed that further addresses the influence of debris concentration and other basal conditions on the behavior of basal ice and its potential influence on the flow and sedimentary dynamics of Matanuska Glacier and other glaciers.

Acknowledgements. This work benefited tremendously from helpful suggestions, discussion and hard work of Daniel Lawson, Grahame Larson, Josh Stachnik and Tom Pasquini. Additional thanks to Tom Pasquini and ExxonMobil for partially funding this research. Endless thanks to Bill and Kelly Stevenson for their graciousness in providing lodging, logistical support and entertainment. This article is IRM publication number 1813 .

\section{References}

Alley RB (1992) Flow-law hypotheses for ice-sheet modeling. Journal of Glaciology 38, 245-256.

Alley RB, Lawson DE, Evenson EB, Strasser J and Larson G (1998) Glaciohydraulic supercooling: a freeze-on mechanism to create stratified, debris-rich basal ice: II. Theory. Journal of Glaciology 44(148), 563-569.

Arcone S, Lawson DE and Delaney A (1995) Short-pulse radar wavelet recovery and resolution of dialectric contrasts within englacial and basal ice of Matanuska Glacier, Alaska, U.S.A.. Journal of Glaciology 41(137), 68-86.

Baker R (1978) The influence of ice crystal zone on creep. Journal of Glaciology 21, 485-497.

Baker G and 5 others (2003) Near-surface seismic reflection profiling of the Matanuska Glacier, Alaska. Geophysics 68(1), 147-156.

Baker R and Bergerich W (1979) The effect of crystal size and dispersed-solid inclusions on the activation energy for creep of ice. Journal of Glaciology 24, 179-194.

Benn DI (1994) Fabric shape and the interpretation of sedimentary fabric data. Journal of Sedimentary Research A64(4), 910-915.

Benn D and Evans DJA (2014) Glaciers and Glaciation, 2nd Edn. Routledge, New York.

Besnus M (1966) Propriétés magnétiques de la pyrrhotine naturelle ( $\mathrm{PhD}$ thesis) University of Strasbourg.

Borradaile GJ (1988) Magnetic susceptibility, petrofabrics, and strain. Tectonophysics 156(1-2), 1-20.

Brugman M (1983) Properties of debris-laden ice: application to the flow response of the glaciers on Mount St. Helens. Annals of Glaciology 4, 297.

Chandler D and Hubbard B (2008) Quantifying sample bias in clast fabric measurements. Sedimentology 55(4), 925-938.

Cohen D (2000) Rheology of ice at the bed of Engabreen, Norway. Journal of Glaciology 46(155), 611-621.

Cuffey KM and Paterson WSB (2010) The Physics of Glaciers, 4th Edn. Butterworth-Heinemann, Burlington, MA.

Cuffey KM, Thorsteinsson T and Waddington E (2000) A renewed argument for crystal size control of ice sheet strain rates. Journal of Geophysical Research 105(B12), 27,889-27,894.

Dash J, Rempel A and Wettlaufer J (2006) The physics of premelted ice and its geophysical consequences. Reviews of Modern Physics 78, 695-741. doi: 10.1103/RevModPhys.78.695.

Dunlop D and Özdemir Ö (1997) Rock Magnetism: Fundamentals and Frontiers. Cambridge Studies in Magnetism. Cambridge: Cambridge University Press, 573 pp.

Echelmeyer K and Zhongxiang W (1987) Direct observation of basal sliding and deformation of basal drift at sub-freezing temperatures. Journal of Glaciology 33, 83-98.

Ensminger S, Alley RB, Evenson EB, Lawson DE and Larson G (2001) Basal-crevasse-fill origin of laminated debris bands at Matanuska Glacier, Alaska, U.S.A. Journal of Glaciology 47(158), 412-422.

Evenson EB and 6 others (1999) Field evidence for the recognition of glaciohydraulic supercooling. Special Paper 337: Glacial Processes Past and Present, pp. 23-35.

Fegyveresi J, Alley RB, Voigt D, Fitzpatrick J and Wilen L (2018) A case study of ice-core bubbles as strain indicators. Annals of Glaciology 60, 8-19. https://doi.org/10.1017/aog.2018.23.

Ferre E, Gebelin A, Till J, Sassier C and Burmeister KC (2014) Deformation and magnetic fabrics in ductile shear zones: a review. Tectonophysics 629, 179-188.

Fisher DA and Koerner R (1986) On the special rheological properties of ancient microparticle-laden Northern Hemisphere ice as derived from borehole and core measurements. Journal of Glaciology 32, 501-510. 
Fleming EJ and 6 others (2013) Magnetic fabrics in the basal ice of a surge-type glacier. Journal of Geophysical Research: Earth Surface 118(4), 2263-2278.

Gentoso M and 6 others (2012) Exploring till bed kinematics using AMS magnetic fabrics and pebble fabrics: the Weedsport Drumlin Field, New York State, USA. Boreas 41, 31-41.

Ghosh S and Ramberg H (1976) Reorientation of inclusions by combination of pure shear and simple shear. Tectonophysics 34, 1-70.

Goldsby DL and Kohlstedt DL (2001) Superplastic deformation of ice: experimental observations. Journal of Geophysical Research - Solid Earth 106(B6), 11017-11030. https://dx.doi.org/10.1029/2000JB900336.

Hart JK (1995) An investigation of the deforming layer/debris-rich basal-ice continuum, illustrated from three Alaska glaciers. Journal of Glaciology $4 \mathbf{1}$ (139), 619-633.

Hart JK (1998) The deformed bed/debris-rich basal-ice continuum and its implications for the formation of glacial landforms (flutes) and sediments (melt-out till). Quaternary Science Reviews 17, 737-754.

Hooke R, Dahlin B and Kauper M (1972) Creep of ice containing dispersed fine sand. Journal of Glaciology 11, 327-336.

Hooyer TS, Iverson N, Lagroix F and Thomason J (2008) Magnetic fabric of a sheared till: a strain indicator for evaluating the bed deformation model of glacier flow. Journal of Geophysical Research 113, F02002. doi: 10.1029/ 2007JF000757.

Hopkins NR, Evenson EB, Kodama K and Kozlowski A. 2016 an anisotropy of magnetic susceptibility (AMS) investigation of the till fabric of drumlins: support for an accretionary origin. Boreas 45(1), 100-108.

Hrouda F (1982) Magnetic anisotropy of rocks and its application in geology and geophysics. Geophysical Surveys 5, 37-82.

Hubbard B and Sharp M (1989) Basal ice formation and deformation: a review. Progress in Physical Geography 13, 529-558.

Ildefonse B and Mancktelow N (1993) Deformation around rigid particles: the influence of slip at the particle/matrix interface. Tectonophysics 221, 345-359. https://doi.org/10.1016/0040-1951(93)90166-H.

Iverson N (2017) Determining glacier flow direction from till fabrics. Geomorphology 299, 124-130.

Iverson N, Hooyer TS, Thomason J, Graesch M and Shumway J (2008) The experimental basis for interpreting particle and magnetic fabrics in sheared till. Earth Surface Processes and Landforms 33, 627-645.

Jacka T and Budd W (1989) A review of ice rheology for ice-sheet modeling. Cold Regions Science and Technology 16(2), 107-144.

Jackson M (1991) Anisotropy of magnetic remanence: a brief review of mineralogical sources, physical origins, and geological applications, and comparison with susceptibility anisotropy. Pure and Applied Geophysics 136 (1), 1-28.

Jelinek V (1981) Characterization of the magnetic fabric of rocks. Tectonophysics 79, 63-67.

Larson G, Menzies J, Lawson DE, Evenson EB and Hopkins NR (2016) Macro- and micro-sedimentology of a modern meltout till - Matanuska Glacier, Alaska, USA. Boreas 45(2), 235-251.

Lawson DE (1979a) A comparison of the pebble orientation in ice and deposits of the Matanuska Glacier, Alaska. Journal of Geology 87(6), 629-645.

Lawson DE (1979b) Sedimentological analysis of the western terminus region of the Matanuska Glacier, Alaska. CRREL Report 79-9, $122 \mathrm{pp}$.

Lawson DE (1979c) Characteristics and origins of the debris and ice, Matanuska Glacier, Alaska. Journal of Glaciology 23(89), 437-438.
Lawson DE (1981) Sedimentological characteristics and classification of depositional processes and deposits in the glacial environment. CRREL Report 81-27, 22 pp.

Lawson DE and 5 others (1998) Glaciohydraulic supercooling: a freeze-on mechanism to create stratified debris-rich basal ice: I. Field evidence. Journal of Glaciology 44(148), 547-562.

Lawson DE and Kulla J (1978) An oxygen isotope investigation of the origin of the basal zone of the Matanuska Glacier, Alaska. The Journal of Geology 86(6), 673-685.

Luthi M, Fahnestock M and Truffer M (2009) Calving iceberg indicate a thick layer of temperate ice at the base of Jakobshavn Isbræ, Greenland. Journal of Glaciology 55(191), 563-566.

March A (1932) Mathematical theory on regulation according to the particle shape and affine deformation. Zeitschrift für Kristallographie 81(3/4), 285-297.

Mark D (1973) Analysis of axial orientation data, including till fabric. Geological Society of America Bulletin 84(4), 1369-1374.

Maxbauer D, Feinberg J and Fox D (2016) MAX unmix: a web application for unmixing magnetic coercivity distributions. Computers \& Geosciences 95, 140-145.

Moore PL (2014) Deformation of debris-ice mixtures. Reviews of Geophysics 52, 435-467.

Nickling WG and Bennet L (1984) The shear strength characteristics of frozen coarse granular debris. Journal of Glaciology 30, 348-357.

Pares J (2004) How deformed are weakly deformed mudrocks? Insights from magnetic anisotropy. Geological Society, London, Special Publications 238, 191-203.

Samyn D, Fitzsimons J and Lorrain RD (2005) Strain-induced phase changes within cold basal ice from Taylor Glacier, Antarctica, indicated by textural and gas analyses. Journal of Glaciology 51(175), 611-619.

Samyn D, Fitzsimons J and Lorrain RD (2009) Rotating microstructures in cold basal ice: implications for glacier flow and its interpretation. International Journal of Earth Science 99(8), 1849-1857.

Samyn D, Svensson A and Fitzsimons S (2008) Dynamic implications of discontinuous recrystallization in cold basal ice: Taylor Glacier, Antarctica. Journal of Geophysical Research 113, F03S90.

Shumway J and Iverson N (2009) Magnetic fabrics of the Douglass till of the superior lobe: exploring bed-deformation kinematics. Quaternary Science Reviews 28, 107-119.

Strasser J, Lawson DE, Larson G, Evenson EB and Alley RB (1998) Preliminary results of tritium analysis in basal ice, Matanuska Glacier, Alaska, U.S.A.: evidence for subglacial accretion. Annals of Glaciology 22, 126-133.

Tarling DH and Hrouda F (1993) The Magnetic Anisotropy of Rocks. London: Chapman \& Hall, 217 pp.

Ting J, Martin R and Ladd C (1983) Mechanisms of strength for frozen sand. Journal of Geotechnical Engineering 109(10), 1286-1302.

Titus D, Strasser J, Lawson DE, Evenson EB and Alley RB (1999) Isotopic composition of vent discharge from the Matanuska Glacier, Alaska. Implication for the origin of basal ice. Geological Society of America Special Paper 337, 37-44.

Verwey EJ (1939) Electrostatic conduction of magnetite (Fe3O4) and its transition point at low temperature. Nature 144, 327-328.

Vreeland N, Iverson N, Graesch M and Hooyer T (2015) Magnetic fabrics of the drumlins of the Green Bay Lobe, southeastern Wisconsin. Quaternary Science Reviews 112, 33-44.

Williams JR and Ferrians OJ (1961) Late Wisconsinan and recent history of the Matanuska glacier, Alaska. Arctic 14, 82-90. 